\title{
Accidental methyl salicylate poisoning in two adults
}

\author{
M P Seneviratne ${ }^{1}$, S Karunarathne ${ }^{1}$, A H de Alwis ${ }^{1}$, A H N Fernando ${ }^{1}$, R Fernando ${ }^{2}$
}

Ceylon Medical Journal 2015; 60: 65

\section{Introduction}

Methyl salicylate (MS) is widely available as a component in many over-the-counter brands of ointments, lotions, liniments and medicated oils intended for topical application [1]. Among the most potent forms of methyl salicylate is oil of wintergreen (98\% MS). Salicylate ointment has a very high concentration of MS. One teaspoon contains $7000 \mathrm{mg}$ MS, equivalent to 90 baby aspirin tablets. We report two adults presenting with accidental MS poisoning. They were admitted with a bottle containing $98 \% \mathrm{MS}$, which they drank assuming it was ethanol.

\section{Case report}

Patient 1 was a 32-year-old man, who was admitted with a history of a sudden syncopal attack after consuming a small amount of MS. His breath smelled of MS. He was restless and hyperventilating. Pulse rate was 140 per minute and blood pressure (BP) was 90/60 mm Hg. Soon after admission he developed a generalised tonic clonic seizure. Oxygen saturation was $100 \%$, Glasgow Coma Scale (GCS) was 6 and arterial blood gas $\mathrm{pH}$ was 7.15.Within two hours, while waiting for haemodialysis (HD), he developed a cardiac arrest and died. The autopsy showed congestion of organs. The smell of MS was present in the gastro-intestinal tract. Blood analysis detected the presence of MS, which was not quantified.

Patient 2 was, a 42-year-old man who had ingested one mouthful (about $10 \mathrm{ml}$ ) of MS. He was admitted with burning epigastric pain. The vomitus had the characteristic smell of MS. He was anxious, restless and tachypnoeic. He had a generalised tonic clonic seizure, after which, he became delirious and had to be restrained physically. The GCS was 13. Pulse rate was 120 per minute, BP was $130 / 80 \mathrm{~mm} \mathrm{Hg}$, respiratory rate was 36 per minute and oxygen saturation was $93 \%$ while on oxygen 61 per minute. He had bilateral basal fine end-inspiratory crepitations and epigastric tenderness. Gastric lavage aspirate smelt of MS. He was given activated charcoal. Convulsions were controlled with intravenous diazepam and midazolam infusions. Investigations showed metabolic acidosis and respiratory alkalosis characteristic of salicylate poisoning. Hypoglycaemia, hypokalaemia, and hyponatraemia were corrected. White cell count was $20,100 / \mathrm{mm}^{3}$ with $89 \%$ neutrophils. Urine $\mathrm{pH}$ was 6.0. Urinalysis showed ketones, $100 \mathrm{mg} / \mathrm{dl}$ protein, pus cells 10-12/high power field (hpf) and red cells $100 / \mathrm{hpf}$. There were few granular casts. Liver profile was aspartate transaminase $=665 \mathrm{u} / 1$, alanine transaminase $=233 \mathrm{u} / 1$, alkaline phosphatase $=243 \mathrm{u} / \mathrm{l}$, and total bilirubin $=11.7$ umol/1. Sodium bicarbonate in 5\% dextrose infusion was commenced at $100 \mathrm{ml} /$ hour to achieve an alkaline diuresis. Patient underwent haemodialysis about two hours after admission. After haemodialysis, the patient's conscious level improved. He went home after four days.

\section{Discussion}

Haemodialysis is widely advocated in managing severe MS intoxication. Patients with severe poisoning may require extended durations of HD [2]. Experimental and clinical studies confirm that urinary alkalinisation increases MS elimination [3]. Deaths of two 4-year-old boys who ingested an unknown quantity of MS liniment have been reported in Sri Lanka before. Despite gastric lavage, anticonvulsant therapy and forced alkaline diuresis, they died within 24 hours [4].

\section{Conflicts of interest}

We declare that there are no conflicts of interest.

\section{References}

1. Davis JE. Are one or two dangerous? Methyl salicylate exposure in toddlers. J Emerg Med 2007; 32: 63-9.

2. MinnsAB, Cantrell FL, Clark RF. Death due to acute salicylate intoxication despite dialysis. JEmerg Med 2011; 40: $515-7$

3. Proudfoot AT, Krenzelok EP, Brent J, Vale JA. Does urine alkalinization increase salicylate elimination? If so, why? Toxicol Rev 2003; 22: 129-36.

4. Lucas GN. Acute drug poisoning in children. Sri Lanka J Child Health 2000; 29: 45-8

${ }^{1}$ National Hospital of Sri Lanka, Colombo and ${ }^{2}$ Department of Forensic Medicine and Toxicology, Faculty of Medicine, University of Colombo, Sri Lanka.

Correspondence: RF, e-mail: <ravindrafernando@hotmail.co.uk>. Received 18 November 2014 and revised version accepted 6 February 2015. 